\title{
STRATEGI PENINGKATAN KESEJAHTERAAN NELAYAN KECIL DI DESA TOKKE KECAMATAN MALANGKE KABUPATEN LUWU UTARA
}

\author{
(Small Fishermen Welfare Improvement Strategy in Tokke \\ Village Malangke District North Luwu Regency) \\ Aqidah $^{1)}$, Rustam ${ }^{2)}$ dan Ernaningsih' ${ }^{2)}$ \\ 1. Dinas Perikanan Kabupaten Luwu Utara \\ 2. Program Studi Manajemen Pesisir dan Teknologi Kelautan, PPS UMI Makassar
}

Korespondensi:aqidahhusain.dkp@gmail.com

Diterima: tanggal 2 Februari 2020; Disetujui 5 Maret 2020

\begin{abstract}
This research was conducted with the aim of (1) Identifying the socio-economic characteristics of small fishermen, (2) Analyzing the welfare level of small fishermen, (3) Formulating strategies to improve the welfare of small fishermen in Tokke Village, Malangke District, North Luwu Regency. This study was analyzed based on each objective. The first objective was analyzed by descriptive analysis using the interview method, questionnaire, documentation and direct observation supported by two data, primary and secondary data. Respondents in this study were all small fishermen in Tokke Village and informants who were considered to know the most problems faced by fishermen in the field. The second objective is analyzed by combining income analysis and welfare indicator analysis, while the third objective is analyzed by the SWOT analysis method. The results showed that fishermen's socioeconomic characteristics were influenced by fishermen's income, fishermen age, education level, fishing facilities and infrastructure used by fishermen. The level of welfare of small fishermen in Tokke Village, Malangke Subdistrict, North Luwu Regency, as many as 34\% of fishing households have a low welfare level and 66\% of fishermen households are at moderate welfare level. Some SWOT analysis strategies are found from various internal and external factors related to improving the welfare of small fishermen, namely the utilization of potential fishery resources, the development of alternative businesses, the development of facilities and infrastructure of the coastal area, alternative livelihoods, development of capital systems, utilization of existing production into processed products. through human resource development.
\end{abstract}

Keywords: Fishermen, Welfare Level, North Luwu Regency

\section{ABSTRAK}

Peningkatan Kesejahteraan Nelayan Kecil di Desa Tokke Kecamatan Malangke Kabupaten Luwu Utara.Penelitian ini dilakukan dengan tujuan : (1) Mengidentifikasi karakteristik social ekonomi nelayan kecil, (2) Menganalisis tingkat kesejahteraan nelayan kecil, (3) Merumuskan strategi peningkatan kesejahteraan nelayan kecil di Desa Tokke Kecamatan Malangke Kabupaten Luwu Utara. Metode penelitian menggunakan metode wawancara, penyebaran angket kuisioner, dokumentasi dan observasi langsung yang didukung dengan dua data yakni data primer dan sekunder. Responden dalam penelitian ini adalah nelayan kecil di Desa Tokke dan narasumber yang dianggap paling banyak mengetahui permasalahan yang dihadapi dilapangan. Data dianalisa dengan menggabungkan analisis pendapatan dan analisis indikator kesejahteraan, serta melakukan analisis SWOT.Hasil penelitian menunjukkan bahwa karakteristik sosial ekonomi nelayan dipengaruhi oleh pendapatan nelayan, usia nelayan, tingkat pendidikan, sarana dan prasarana penangkapan yang digunakan oleh nelayan. Tingkat kesejahteraan nelayan kecil di Desa Tokke Kecamatan Malangke Kabupaten Luwu Utara yaitu sebanyak 34\% rumah tangga nelayan memiliki tingkat kesejahteraan rendah dan $66 \%$ rumah tangga nelayan pada tingkat kesejahteraan sedang. Beberapa strategi analisis SWOT ditemukan dari berbagai factor internal maupun eksternal yang berkaitan dengan peningkatan kesejahteraan nelayan kecil yaitu pemanfaatan potensi sumberdaya perikanan, pengembangan usaha alternative, pengembangan sarana dan prasarana kawasan pesisir, mata pencaharian alternative, pengembangan system permodalan, pemanfaatan produksi yang ada menjadi produk olahan melalui pengembangan sumber daya manusia.

Kata kunci: Nelayan, Tingkat Kesejahteraan, Kabupaten Luwu Utara 


\section{PENDAHULUAN}

Pemberdayaan masyarakat pesisir merupakan salah satu upaya untuk meningkatkan kesejahteraan nelayan. Potensi dan produktivitas sumber daya perikanan yang melimpah tidak serta merta membuat kesejahteraan nelayan terjamin.Hasil-hasil studi tentang tingkat kesejahteraan hidup dikalangan masyarakat nelayan, telah menunjukkan bahwa kemiskinan dan kesenjangan sosial ekonomi atau ketimpangan pendapatan merupakan persoalan krusial yang dihadapi nelayan dan tidak mudah untuk diatasi.Dalam rangka mengatasi degradasi sumber daya perikanan kelautan di Indonesia, khususnya di Desa Tokke Kecamatan Malangke diperlukan suatu desain pengelolaan yang komprehensif. Desain pengelolaan ini diharapkan dapat menyatukan beberapa kebijakan yang ada sehingga dapat mengakomodasi kebutuhan masyarakat. Untuk maksud tersebut, maka diperlukan adanya pengelolaan wilayah laut dan pesisir desa secara terpadu dan berkelanjutan, dengan berdasar pada kajian potensi suberdaya alam, kondisi biogeofisik dan lingkungan, penggunaan lahan kawasan pesisir, sosial ekonomi dan budaya masyarakat di pesisir dan lautan Kabupaten Luwu Utara.

Penelitian ini bertujuan untuk mengidentifikasi karakteristik sosial ekonomi nelayan, menganalisis tingkat kesejahteraan nelayan kecil di Desa Tokke Kecamatan Malangke Kabupaten Luwu Utara, dan merumuskan strategi peningkatan kesejahteraan nelayan kecil di Desa Tokke Kabupaten Luwu Utara. Penelitian ini diharapkan mampu memberikan gambaran terkait analisis pengembangan social ekonomi nelayan kecil serta menjadi bahan masukan kepada Pemerintah dalam mengambil kebijakan terkait kegiatan perikanan tangkap dalam hal penyusunan rencana dan pelaksanaan kegiatan yang tepat untuk peningkatan kesejahteraan nelayan kecil.

\section{MATERI DAN METODE}

Penelitian ini dilaksanakan di wilayah pesisir tepatnya di Desa Tokke Kecamatan Malangke Kabupaten Luwu Utara selama \pm 1 bulan yaitu bulan Agustus sampai dengan Sepetember 2019. Adapun lokasi penelitian sebagai berikut: 


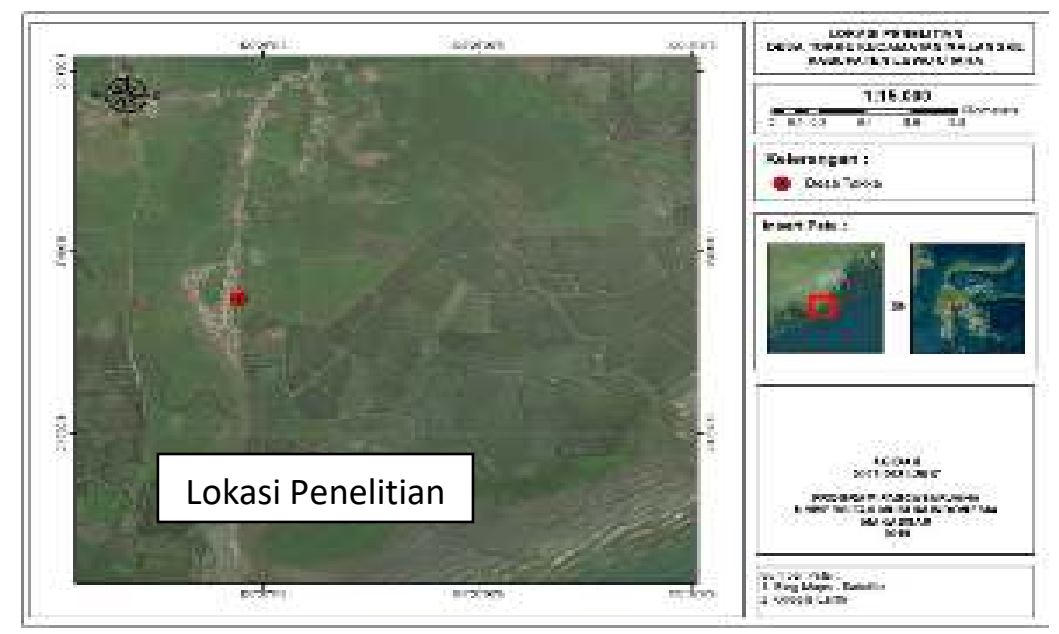

Gambar 1. Peta Lokasi Penelitian

Penelitian ini dikembangkan digunakan dalam penelitian ini adalah melalui metode survey yang sumber unit analisa individu nelayan dari datanya merupakan data primer dan keluarga dengan mata pencaharian data sekunder.Data primer adalah data utamanya sebagai nelayan. Responden yang diperoleh langsung dari responden akan diwawancarai menggunakan dengan cara pengisian kuisioner, kuesioner yang telah dibuat. Jawaban wawancara, observasi lapangan dan yang diperoleh dari kuesioner dianggap pengumpulan data, sedangkan data dapat mewakili kondisi rumah tangga sekunderatau data penunjang adalah nelayan pesisir. Responden data yang dikumpulkan dari memberikan informasi terkait dengan kepustakaan dan ekonomi dari instansi dirinya. Pemilihan unit analisa ini pemerinth terkait seperti kantor Desa dikarenakan peningkatan pendapatan Tokke, kantor Kecamatan Malangke, keluarga erat kaitannya dengan kondisi Dinas Perikanan Kabupaten Luwu rumah tangga. Pemilihan responden Utara. Metode pengumpulan data diambil dengan metode sensus.

dilakukan dengan cara : studi Data yang ddikumpulkan di kepustakaan, observasi langsung, analisis secara Deskritif kualitatif dan wawancara, penentuan bobot, serta kuantitatif.Untuk mendapatkan hasil dokumentasi. penelitian yang cermat dan teliti

Data yang diambil dalam dilakukan pendekatan studi secara penelitian ini bersumber dari responden bertahap.Tahap awal, mengidentifikasi dan informan. Unit analisa yang dan menganalisis tingkat kesejahteraan 
nelayan di wilayah pesisir Desa Tokke, untuk menghadapi ancaman yang akan faktor-faktor yang diamati dan datang(WT).

dilakukan evaluasi yang berhubungan dengan kegiatan pemanfaatan sumberdaya perikanan khususnya kegiatan nelayan skala kecil.

Analisis pendapatan dan indikator kesejahteraan, dilakukan untuk menghitung pendapatan rumah tangga nelayan-nelayan kecil di Desa Tokke Kecamatan Malangke. Menghitung pendapatan nelayan skala kecil dilakukan dengan pendekatan keuntungan. Keuntungan adalah selisih antara penerimaan total dan biaya total.

Analisis SWOT yaitu meliputi (Strenght, Weakness, Oppurtunities, dan Threats), Penggunaan analisis matriks SWOT merupakan suatu analisis untuk menentukan strategi yang paling tepat. Alternatif strategi pada matriks hasil analisis SWOT seperti disajikan pada table dihasilkan dari: penggunaan unsur-unsur kekuatan kawasan untuk mendapatkan peluang yang ada (SO), penggunaan kekuatan yang ada untuk menghadapi ancaman yang akan datang (ST), pengurangan kelemahan kawasan yang ada dengan memanfaatkan peluang yang ada (WO) dan pengurangan kelemahan yang ada

\section{HASIL DAN PEMBAHASAN}

Desa Tokke berada dalam wilayah pemerintahan Kecamatan Malangke, Daerah Tingkat II Kabupaten Luwu Utara yang merupakan salah satu desa yang berada di Wilayah Pesisir Teluk Bone yang berjarak $37,50 \mathrm{Km}$ dari Ibukota Kabupaten Luwu Utara dan berjarak 9,50 Km dari Ibukota Kecamatan Malangke.

\section{- Karakteristik Sosial Ekonomi Lokasi Penelitian}

1. Jumlah Penduduk, Agama dan Etnis Jumlah Penduduk Desa Tokke Kecamatan Malangke pada Tahun 2018 sebanyak 1691 Jiwa yang terdiri dari 862 Jiwa laki-laki dan 829 jiwa perempuan dengan jumlah Rumah Tangga sebanyak 380. Adapun Jumlah Rumah Tangga Perikanan sebanyak 122 RT, dan yang memiliki kapal $\leq 10$ GT sebanyak 106 rumah tangga. Dari data ini terlihat bahwa sekitar $30 \%$ Rumah Tangga di Desa Tokke adalah Rumah Tangga Perikanan (Nelayan). Mayoritas penduduk Desa Tokke menggunakan bahasa bugis sebagai bahasa sehari-hari. Wilayah pesisir Desa Tokke di huni penduduk yang 
mayoritas memeluk agama Islam (Data pada kisaran yang termuda berusia 24 BPS Luwu Utara, 2018) tahun dan yang tertua berusia 66 tahun. Umur berkorelasi dengan pengalaman

2. Usia Nelayan

Umur Nelayan yang menjadi responden dalam penelitian ini berada berikut:

Tabel 1. Kelompok Umur Nelayan Desa Tokke Kecamatan Malangke

\begin{tabular}{cc}
\hline Kelompok Umur (Tahun) & Jumlah Nelayan (Orang) \\
\hline $24-33$ & 16 \\
$34-43$ & 37 \\
$44-53$ & 33 \\
$54-63$ & 14 \\
$>67$ & 6 \\
\hline Total & 102 \\
\hline
\end{tabular}

Sumber: Hasil olahan Data Primer 2019

Kondisi ini merupakan potret tingkat dari jumlah responden. Kondisi ini pengalaman yang ada dikalangan merupakan potret tingkat pendidikan nelayan pada umumnya. Johannes, et umumnya yang ada di nelayan adalah al. (2000) menyatakan semakin tingkat pendidikan yang rendah berumur nelayan mala pengalaman (Ahmad et. Al 2013).

yang dimilikinya terakumulasi menjadi suatu asset pengetahuan tradisional 4. Jenis Alat Tangkap Nelayan

Setelah melakukan observasi di ekologi yang sangat berharga atau lapangan dan wawancara langsung dikenal dengan istilah fisher's dengan responden maka teridentifikasi ecological knowledge.

\section{Pendidikan Nelayan}

Tingkat pendidikan nelayan kecil di Desa Tokke Kecamatan Malangke sebagian besar berhasil menamatkan tingkat Sekolah Dasar (SD) sebanyak 94 orang $(88,7 \%)$ dari 106 responden, sedangkan nelayan yang berpendidikan SMP berjumlah 10 orang $(9,4 \%)$ dan berpendidikan SMA 2 orang $(1,9 \%)$ jenis alat tangkap yang sering digunakan nelayan kecil di Desa Tokke yaitualat tangkap gill net atau biasa disebut jarring insang, pancing, pukat dan bubu.Dari 106 Responden, sebanyak 1 orang menggunakan Gill net, 45 nelayan menggunakan pancing, 8 orang menngunakan bubu dan 52 nelayan menggunakan jenis pukat sebagai alat tangkapnya. Jenis dan 
Jumlah alat tangkap nelayan di Desa lihat pada Tabel berikut.

Tokke Kecamatan Malangke dapat di

Tabel 2. Jenis dan Jumlah Alat tangkap Nelayan Desa Tokke

\begin{tabular}{|c|c|}
\hline Jenis Alat tangkap & Jumlah \\
\hline Gill Net & 1 \\
\hline Pancing & 45 \\
\hline Bubu & 8 \\
\hline Pukat & 52 \\
\hline Total & 106 \\
\hline
\end{tabular}

Alat tangkap yang digunakan perahu nelayan yang belum memadai. oleh nelayan di Desa Tokke umumnya Berdasarkan hasil wawancara dengan terdiri dari pancing, gill net, pukat dan nelayan, di Desa Tokke ada dermaga bubu. Alat tangkap yang paling atau pangkalan pendaratan ikan yang dominan digunakan nelayan di Desa dibangun oleh Pemerintah Daerah Tokke adalah jenis pancing dan pukat. Kabupaten Luwu Utara namun Jenis pancing yang digunakan antar lain pembangunannya terhenti karena pancing tonda dan pancing ulur terkendala anggaran dan belum dapat sedangkan jenis pukat yang digunakan digunakan atau difungsikan adalah payang, purse seine, dan pukat sebagaimana mestinya. Oleh karenanya cincin. Adapun Jenis ikan yang nelayan setempat menggunakan tambat ditangkap antaralain ikan kembung, labuh yang belum memadai yang ikan layang, ikan cakalang, ikan kakap, dibangun secara swadaya bersama ikan tenggiri dan ikan putih. pemerintah desa dan nelayan setempat.

Dari hasil pengamatan dan 6. Ekonomi dan Sumber Pendapatan wawancara jenis tangkapan nelayan Nelayan

cukup beragam dan alat tangkap yang

Masyarakat pesisir selalu identik digunakan bermacam-macam. Hal ini dengan kemiskinan walaupun daerah menjadikana pengelolaannya bersifat tersebut kaya dengan sumberdaya alam kompleks dan sulit penanganannya yang berlimpah, namun kenyataannya (Jones et al. 2011). masyarakat yang bermukim di wilayah

5. Infrastruktur dan Prasarana Pesisir pesisir sebagian besar justru hidup di

Di Desa Tokke Kecamatan bawah garis kemiskinan dan menjadi Malangke terdapat infrastruktur dan golongan yang terpinggirkan. prasarana pesisir berupa tambat labuh 
Di Desa Tokke terdapat 8 kapal, lama operasi, jenis ikan yang Kelompok nelayan yang merupakan ditangkap, lokasi fishing ground dan binaan dari Dinas Perikanan Kabupaten musim. Hasil tangkapan sebagian besar Luwu Utara. Kelompok-kelompok di jual kepada pengumpul yang ada di tersebut merupakan nelayan-nelayan Desa Tokke Kecamatan Malangke.

yang ada di Desa Tokke yang - Kesejahteraan Nelayan Kecil di melakukan kegiatan penangkapan ikan Desa Tokke

secara produktif dan sumber Tingkat Kesejahteraan Nelayan di pendapatannya berasal dari hasil melaut atau menangkap ikan.

Desa Tokke Kecamatan Malangke, jika Nelayan di Desa Tokke digunakan BPS dalam Yafiz (2011). menangkap ikan dengan memanfaatkan Berdasarkan hasil observasi dan sumberdaya perikanan di sekitar wawancara dengan responden dilokasi perairan Teluk Bone. Nelayan kecil penelitian, maka secara umum yang ada di Desa Tokke menangkap diketahui indikator kesejahteraan ikan sampai batas 4 mil yang sesuai nelayan di Desa Tokke diuraikan dengan kapasitas bobot kapalnya \pm 5 berikut ini.

GT. Kapal yang dioperasikan nelayan 1. Pendapatan Rumah Tangga

di Desa Tokke tidak dilengkapi dengan Tolak ukur yang digunakan peralatan navigasi seperti kompas adalah besarnya rata - rata pendapatan maupun radio komunikasi. Hal ini rumah tangga nelayan per bulan. disebabkan karena lokasi operasi Perhitungan pendapatan rata-rata penangkapan tidak terlalu jauh dan perbulan dari responden diketahui masih berskala tradisional, hanya bahwa 11 orang ( $10,4 \%)$ sebagian kecil nelayan yang telah berpendapatan tinggi yang jumlah memakai GPS sebagai alat bantu dalam pendapatannya lebih dari Rp. operasi penangkapan ikan. $\quad 1.720 .000$,-sebanyak 38 orang $(35,8 \%)$

Pada umumnya nelayan di Desa berpendapatan sedang dengan jumlah Tokke berangkat melaut pada malam pendapatan Rp.860.000,- sampai hari dan pulang di esok siang atau sore dengan Rp 1.720.000,- dan 57 orang hari. Jumlah ikan yang ditangkap $(53,8 \%)$ berpendapatan rendah atau beragam tergntung pada kapasitas memiliki pendapatan kurang dari Rp. 
860.000,- perbulannya. Menurut Pana memiliki tempat tinggal semi permanen dan Siasu (2012) bahwa hasil dari 45 orang (42,5\%) sedangkan non pendapatan menangkap ikan umumnya permanen hanya 5 orang. digunakan untuk memenuhi kebutuhan 4. Migrasi (Perpindahan) dasar hidup nelayan dan keluarganya.

Hasil observasi dan wawancara 2. Konsumsi Rumah Tangga diketahui bahwa sebagian besar nelayan

Dari hasil wawancara sebanyak di desa Tokke yaitu sebanyak 101 44 orang $(41,5 \%)$ keluarga nelayan orang $(95,3 \%)$ nelayan kecil di Desa yang mengkonsumsi beras lebih dari Tokke tidak pernah melakukan migrasi $480 \mathrm{~kg}$ /tahun dan rumah tangga ini (perpindahan), sebanyak 5 orang dikategorikan kelompok keluarga tidak nelayan (4,7\%) yang melakukan miskin, ada 59 orang (55.7\%) perpindahan 1 sampai 2 kali dan tidak keluarga nelayan yang dikategorikan ada nelayan di Desa Tokke yang sering sebagai keluarga miskin karena melakukan perpindahan. Sehingga dari mengkonsumsi beras sekitar $380-480$ hasil pengamatan sebagian besar $\mathrm{Kg}$ /Tahun dan hanya 3 orang $(2,8 \%)$ nelayan kecil di Desa Tokke tidak yang dikategorikan dalam kelompok pernah berimigrasi.

keluarga miskin sekali karena Menurut Sugiharto (2007) mengkonsumsi beras kurang dari 380 migrasi atau perpindahan tidak terjadi $\mathrm{Kg}$ /tahun.

pada komunitas nelayan jika di daerah

3. Keadaan Pemukiman mereka tinggal ada sumber mata Kondisi tempat tinggal bagi pencaharian yang dapat member masyarakat di Negara-negara penghasilan bagi nelayan dan berkembang dapat mencerminkan keluarganya.

status social mereka (Cinner dan 5. Kesehatan Anggota Keluarga

Pollnac 2004). Pada umumnya Dari hasil wawancara sebanyak gambaran kondisi pemukiman nelayan 16 orang responden (15\%) yang ada di di Desa Tokke atau sebagian besar Desa Tokke yang mempunyai adalah bangunan semi permanen dan kesehatan anggota keluargasangat baik, permanen. Nelayan yang tinggal ada 90 orang responden atau $85 \%$ dibangunan permanen sebanyak 56 nelayan yang menyatakan kondisi orang $(52,8 \%)$ nelayan dan yang kesehatan cukup baik atau kadang ada 
yang sakit dan tidak ada responden terlihat bahwa nelayan di Desa Tokke yang menyatakan bahwa anggota cukup terampil dalam hal penguasaan keluarganya sering sakit. Hal ini pengoperasian kapal dan alat tangkap menunjukkan bahwa kesadaran yang seharusnya dimiliki oleh nelayan masyarakat nelayan akan lingkungan untuk peningkatan produksi yang bersih dan sehat sudah cukup penangkapan ikan.

tinggi. Hal ini disebabkan pemerintah 8. Kemudahan Mendapat Pekerjaan setempat giat melakukan penyuluhan Hasil wawancara responden kesehatan, sanitasi, penyediaan air nelayan di desa Tokke diketahui bahwa bersih. Disamping itu pelayanan 86 orang (81\%) nelayan tidak memiliki kesehatan di Desa Tokke cukup baik pekerjaan alternative. Hanya 17 orang oleh petugas kesehatan.

6. Kemudahan Anak mendapat
Pendidikan
atau $(16,2 \%)$ orang yang mudah Hasil penelitian diketahui bahwa $(2,8 \%)$ dari jumlah responden yang ada 11 orang $(10,4 \%)$ nelayan yang menyatakan cukup mudah memasukkan anak ke suatu jenjang pendidikan dan sebanyak 95 orang responden $(89,6 \%)$ menyatakan cukup mudah mendapatkan pekerjaan. Pada musim peceklik nelayan di Desa Tokke sebagian besar tidak memiliki nelayan yang menyatakan mudah serta pekerjaan alternative yang lain. tidak ada responden atau nelayan di Menurut Sugiharto (2007) nelayan Desa Tokke yang menyatakan sulit karena memasukkan anak ke suatu jenjang keterampilan lain yang terbatas serta pendidikan. tidak adanya modal usaha dan lapangan

7. Keterampilan

Hasil wawancara dengan pekerjaan lain sulit didapatkan. Mereka responden sebanyak 52 orang $(49 \%)$ dengan tetap melakukan aktivitas yang nelayan yang menguasai lebih dari 3 berhubungan dengan profesi nelayan jenis keterampilan dibidang perikanan seperti beraktifitas di muara sungai dan sebanyak 54 orang (51\%) nelayan mencari kepiting, rajungan, kerangyang menguasai 2 - 3 keterampilan di kerangan dan memancing ikan.

bidang perikanan. Dari Hasil ini 
9. Konflik di Lingkungan Nelayan Tokke jarang terjadi disebabkan Hasil wawancara dengan sebagian besar masih memiliki responden diketahui bahwa di hubungan keluarga atau kekerabatan Llingkungan nelayan Desa Tokke yang cukup dekat. jarang terjadi konflik. Sebanyak 17 - Tingkat Kesejahteraan Nelayan orang atau 16\% dari 106 responden Kecil di Desa Tokke menyatakan bahwa tidak pernah terjadi Berdasarkan 9 indikator yang konflik dan sebanyak 89 orang (84\%) telah diuraikan di atas, maka Tingkat yang menyatakan jarang terjadi konflik. Kesejahteraan Nelayan kecil di Desa Rasa aman dan nyaman bermukim Tokke Kecamatan Malangke disuatu daerah menciptakan kehidupan Kabupaten Luwu Utara dapat di lihat social yang selaras dan kompak. pada lampiran 4 dan disajikan pada Konflik dilingkungan nelayan Desa tabel di bawah ini.

Tabel 3. Tingkat Kesejahteraan Nelayan Kecil di Desa Tokke

\begin{tabular}{ccc}
\hline Tingkat Kesejahteraan & Jumlah & Persen (\%) \\
\hline Rendah & 36 & 34 \\
Sedang & 70 & 66 \\
Tinggi & - & \\
\hline Jumlah & 106 & 100
\end{tabular}

Berdasarkan hasil pengamatan

Penyusunan strategi peningkatan dan wawancara dengan responden di kesejahteraan nelayan di Desa Tokke Desa Tokke, diketahui sekitar 34\% atau Kecamatan Malangke dianalisis dengan 36 rumah tangga nelayan kecil masih menggunakan SWOT (Strength, berada pada tingkat kesejahteraan Weakness, Opportunity, and rendah, $66 \%$ atau 70 rumah tangga Threats).Unsur kekuatan (Strength) nelayan kecil di lokasi penelitian antara lain : Potensi sumberdaya memiliki tingkat kesejahteraan perikanan, Sumber daya manusia, serta kesejahteraan sedang dan tidak ada Potensi pendapatan usaha perikanan nelayan kecil di Desa Tokke yang tangkap. Unsur kelemahan (Weakness) memiliki tingkat kesejahteraan tinggi. antara lain : Terbatasnya Sarana dan - Strategi peningkatan prasarana, Rendahnya pendidikan Kesejahteraan Nelayan Kecil nelayan, serta Pengeluaran/konsumsi rumah tangga. Unsur peluang 
(Opportunity) antara lain : Dukungan yaitu memanfaatkan Potensi Pemerintah daerah, Dukungan dan sumberdaya perikanan yang dimiliki partisipasi masyarakat, serta Usaha untuk membuat usaha alternative. Unsur ancaman (Threats) alternative,pembangunan sarana dan antara lain : Cuaca dan musim buruk, prasarana, pengembangan system Konflik lingkungan, serta Kurangnya permodalan melalui koperasi, dan akses permodalan. memanfaatkan hasil produksi menjadi

Ada dua arahan strategi yang produk olahan.

menjadi prioritas utama dalam SARAN peningkatan kesejahteraan nelayan kecil yaitu : 1) Dengan memanfaatkan potensi sumberdaya perikanan dan potensi pendapatan usaha perikanan tangkap untuk membuat usaha alternativedan 2)Pembangunan sarana dan prasarana

\section{KESIMPULAN}

Karakteristik sosial ekonomi nelayan dipengaruhi oleh letak geografis, jumlah /populasi nelayan, usia nelayan dan tingkat pendidikan nelayan serta ketersediaan sarana dan prasarana penangkapan ikan. Kondisi Rumah Tangga Nelayan Kecil di Desa Tokke Kecamatan Malangke sebagian besar memiliki tingkat kesejahteraan sedang yaitu sebanyak $66 \%$, dan nelayan yang memiliki tingkat kesejahteraan rendah sebanyak 34 $\%$.Strategi yang berkaitan dengan peningkatan kesejahteraan di Desa Tokke berdasarkan analisis SWOT

Sebaiknya pemerintah daerah dan pihak-pihak terkait memprioritaskan perbaikan sarana dan prasarana penangkapan ikan di wilayah pesisir dan mengoptimalkan upaya-upaya untuk pendampingan dan peningkatan kualitas sumber daya manusia (nelayan) melalui program-program pemberdayaan nelayan.

\section{UCAPAN TERIMA KASIH}

Tulisan ini merupakan bagian dari penelitian Tesis dan penulis mengucapkan terima kasih kepada Ketua Prodi Manajemen Pesisir dan Teknologi Kelautan, Dosen Pasca Sarjana dan Direktur Pasca Sarjana serta Pemerintah Kabupaten Luwu Utara yang telah memberi kesempatan untuk melanjutkan pendidikan di PPS UMI.

\section{DAFTAR PUSTAKA}

Ahmad N, Rahman S, Bunting AW, Brugere C. 2013. Socio- 
economic and ecological challenges of small-scale fishing and strategies for its sustainable management: a case Study of the Old Brahmaputra River, Bangladesh. Singapore, Journal of Tropical Geography. 34:86102.doi:10.1111/sjtg. 12015

Cinner JE dan Pollnac RB. 2004. Poverty, Perception and Planning : socioeconomics matter in the management of Mexican reefs. Ocean \& Coastal Management. 47:479493.. Marine Policy 37 : 20 27

Johannes RE, Freeman MMR, Hamilton RJ. 2000. Ignore fisher's knowledge and miss the boat. Fish and Fisheries 1 :257-271

Jones EV, Gray TS, Umponstira C. 2010. Small-scale Fishing : Perceptions and Threats to conserving a livelihoods. .3(1): $1-7$

Kusnadi. 2002. Akar Kemiskinan Nelayan. LKIS. Yogyakarta.

Satria A. 2002. Pengantar Sosiologi Masyarakat Pesisir. Jakarta (ID) : Cidesindo.

Sugiharto E. 2007. Tingkat Kesejahteraan Nelayan Desa Benua Baru Ilir Berdasarkan Indikator Badan Pusat Statistik. EPP. Vol 4 No.2 :32-36

Suseno. 2004. Analisis Kebijakan Pengelolaan Perikanan
Tangkap : Kasus di Pantai Utara Jawa Tengah (Disertasi), Bogor (ID) : Institut Pertanian Bogor.

Widodo S. 2009. Strategi Nafkah Rumah Tangga Miskin di Daerah Pesisir. (tesis). Bogor (ID): Sekolah Pascasarjana, Institut Pertanian Bogor.

Wiyono ES. 2009. Persepsi Nelayan Terhadap Sumberdaya Ikan. SOCA 9 (3) : 330-334

Yafiz M. 2011. Perbaikan Kesejahteraan Nelayan melalui Usaha Perikanan di kabupaten Rokan Hilir Provinsi Riau (disertasi). Bogor : Institut Pertanian Bogor.

Zuriat, 2016. Analisis Pendapatan Nelayan pada Kapal Motor 5 10 GT Di Kabupaten Aceh Barat Daya; Jurnal Perikanan Tropis, Volume 3. 